\title{
Manual de los Reglamentos del Agua en Florida: Eliminación y Tratamiento de Aguas Residuales En-Sitio ${ }^{1}$
}

Michael T. Olexa, Luke D'Isernia, Laura Minton, Dulcy Miller y Sara Corbett ${ }^{2}$

\section{Prefacio}

Este manual esta diseñado para proporcionar un resúmen autorizado, exacto y actual de las principales leyes Federales y de Florida que están directa o indirectamente relacionadas a la agricultura. Este manual debe proveer una vista general de los muchos derechos y responsabilidades que tienen los agricultores y propietarios de tierras agrícolas bajo las leyes tanto Federal como de Florida, así como también la información de los contactos apropiados para obtenerla con más detalle. Sin embargo, el lector debe estar advertido de que algunas partes de esta publicación podrían volverse obsoletas en cualquier momento, debido a que las leyes, reglas administrativas, y decisiones de la corte, sobre las cuales se basa este manual, se encuentran bajo revisión constante. Algunos detalles de las leyes citadas no se mencionan, debido a limitaciones de espacio.
Este manual es distribuido con la aclaración de que los autores no intentan proporcionar una asesoría legal o profesional, y que la información contenida aquí no debe ser considerada como un sustituto de asesoría profesional. En este manual, no se incluye toda la información para llevar a cabo el cumplimiento de las leyes Federales y de Florida y los reglamentos que rigen la protección del agua. Por estas razones, el uso de estos materiales por cualquier persona, constituyen un acuerdo para mantener libre de perjuicios a los autores, al Servicio de Extensión Cooperativa de Florida, al Instituto de los Alimentos y Ciencias Agrícolas y a la Universidad de Florida por reclamos de responsabilidad, daños o gastos provenientes de quien sea, por haberse referido o basado en la información contenida en este manual.

1. Este es el documento EDIS FE097, una publicación de Food and Resource Economics Department, Florida Cooperative Extension Service, Institute of Food and Agricultural Sciences, University of Florida, Gainesville, FL. Publicado Noviembre 2006. Por favor visite la página electrónica de EDIS en http://edis.ifas.ufl.edu.

2. Michael T. Olexa, profesor, Food and Resource Economics Department y director, Agricultural Law Center, University of Florida, Gainesville, FL, y presidente, Agricultural Law Committee, The Florida Bar; Luke D'Isernia, alumni, Levin CoIlege of Law, University of Florida, Gainesville, FL; Laura Minton, abogado, Dean, Mead, Egerton, Bloodworth, Capouano y Bozarth, PA, Orlando FL; Dulcy Miller, abogado, Foley and Lardner, LLP, Orlando, FL; y Sarah Corbett, abogado, Florida Second District Court of Appeal, Lakeland, FL. La traducción del ingles al español estuvo a cargo de Filiberto Reyes-Villanueva.

EI Instituto de Alimentos y Ciencias Agrícolas es un empleador que opera bajo Acción Afirmativa y provee Oportunidades Igualitarias, autorizado a proveer investigación, información educativa y otros servicios, únicamente a los individuos e instituciones que operan sin discriminación alguna con relación al credo, color, religión, edad, incapacidad, sexo, orientación sexual, estado civil, nacionalidad, opinion política o afiliaciones. Para más información sobre como obtener otras publicaciones de extensión, comuníquese con la oficina de Servicio de Extensión de su condado. Servicio de Extensión de la Florida / Instituto de Alimentos y Ciencias Agrícolas / Universidad de la Florida / Larry Arrington, Decano. 


\section{¿Quién Regula la Eliminación y Tratamiento de las Aguas Residuales En-Sitio?}

Mientras los Estatutos de Florida tienen una amplia gama de guías para regular la eliminación y tratamiento de aguas residuales; el Departamento de Salud de Florida (DSF), es la autoridad primaria de las regulaciones especificas en todo el estado, controlando la instalación y uso de los sistemas de eliminación y tratamiento de las aguas residuales en-sitio (tanques sépticos y campos de drenaje).

La instalación y uso de los sistemas de eliminación y tratamiento de las aguas residuales en-sitio (SETAROS), también caen bajo el permiso de la autoridad del Departamento de Protección Ambiental (DPA), bajo la Ley del Agua Limpia (LAL) y la Ley del Agua Potable Segura (LAPS). Este es el caso, especialmente cuando un SETAROS y/o un campo de drenaje de un SETAROS son instalados en un pantano, o cuando la falla (o la fuga) de un SETAROS podría amenazar la calidad del agua subterránea y/o el agua superficial con contaminantes, y hacer el agua publica de pozo, insegura para el consumo humano.

El DPA puede regular un SETEROS, de acuerdo a la LAPS, como un Pozo Clase Cinco y requerirlo para reunir los requerimientos del Programa de Control de Inyección Subterráneo (CIS), si cada una de las siguientes condiciones es reunida:

1. Los SETAROS, a pesar de su tamaño reciben cualquier cantidad de agua residual industrial o comercial.

\section{Los SETAROS reciben solamente desechos} sanitarios de residencias familiares múltiples o establecimientos no residenciales, y tienen la capacidad para servir a veinte o más personas por día (también conocido como el sistema de eliminación y tratamiento de aguas residuales de mayor capacidad).

Si es reunida cualquier condición, entonces el propietario u operador de los SETAROS debe reunir los requisitos estatales y al menos, los mínimos requerimientos federales para los pozos de Quinta Clase, como sigue:
- Cumplir con la ejecución de los estándares no peligrosos, prohibiendo la inyección que permita el movimiento de los fluidos que contienen cualquier contaminante, dentro de las fuentes subterráneas del agua potable, si la presencia de ese contaminante puede causar una violación de cualquier regulación primaria de agua potable o adversamente afectar la salud publica; y

- Proveer información de inventario (incluyendo el nombre y ubicación de la instalación, nombre del contacto legal y dirección, información del propietario, naturaleza y tipos de pozos de inyección y estado operativo de los mismos) al estado o APA regional y Programa CIS.

Las reglas de eliminación de desecho del Departamento de Protección Ambiental (DPA) se aplicaran como sigue:

- El volumen estimado de agua residual doméstica procesada, se excede de 10.000 galones por día.

- El estimado de volumen de agua residual comercial procesada, se excede de 5.000 galones por día.

- El agua que contiene o que contendrá desecho peligroso industrial.

Si el sistema falla en una de esas categorías, el DPA probablemente requerirá de un permiso separado e impondrá otras restricciones al sistema. Además de las reglas de todo el estado, los gobiernos locales pueden tener reglas y requerimientos más estrictos para permitir y regular el sistema de eliminación.

\section{¿Son Aceptabales los Sistemas de Eliminación y Tratamiento de las Aguas Residuales En-Sitio?}

El estado no fomenta el uso de los sistemas de eliminación y tratamiento de las aguas residuales en-sitio cuando el uso de los sistemas públicos o inversores-propietarios está disponible fácilmente. Tanto los estatutos como las reglas del DSF requieren 
el uso de los sistemas públicos o

inversores-propietarios en las áreas donde son fácilmente disponibles cuando la instalación de tubería de una casa o negocio esta actualmente capacitado de ser conectado a esos sistemas.

A menos que el sistema este autorizado por el sistema de servicio y esta siendo usado para la eliminación de aguas - grises solamente, este debe ser conectado al sistema de drenaje público dentro de la fecha del año en que tal sistema público se hizo disponible en el área.

Las aguas-Grises y las aguas-Negras son definidas como sigue:

- El agua-Gris es el agua residual residencial de los baños, lavatorios, lavanderías y fregaderos, excepto los fregaderos de las cocinas.

- El agua-Negra es la parte de los desagües domésticos descargados de los inodoros, urinarios y drenajes de las cocinas.

\section{¿Dónde Deben Ser Ubicados los SETAROS?}

La ubicación de un SETARO es un factor clave en la determinación del daño potencial de las aguas subterráneas como se indica:

1. Los SETAROS deben ser colocados a menos de 75 pies de los pozos potables privados, de los pozos de agua de familias-múltiples, de las aguas superficiales, incluyendo los lagos, bahías y los drenajes acequias normalmente húmedas.

2. Los SETAROS deben ser colocados a 100 pies de los pozos de agua potable pública que sirven a establecimientos residenciales y no residenciales, teniendo un flujo total de drenaje menor o igual a 2,000 galones por día.

3. Los SETAROS deben ser colocados a 200 pies de los pozos de agua potable pública que sirven a establecimientos residenciales y no residenciales, teniendo un flujo total de drenaje mayor 2,000 galones por día.
4. Los SETAROS no pueden colocarse debajo de los edificios. Estos deben ser colocados a cinco pies de las bases de los edificios, los muros de las casas móviles, las paredes de las piscinas o líneas de propiedades, excepto donde estas líneas colinden con los servicios de las empresas publicas, las cuales no contienen servicios de aguas subterráneas, o donde los servicios registrados están suministrados específicamente por los sistemas de instalación, para servir a mas de un lote o propiedad.

5. Los SETAROS deben se colocados a 50 pies de los pozos de agua no potable.

6. Los SETAROS deben ser colocados a 10 pies de la tubería de desaguie de agua de lluvia.

7. Los SETAROS deben ser colocados a 11 pies de los tanques de almacenamiento de agua que están en contacto con el suelo o con las líneas de agua potable, a menos que tales líneas sean selladas con un sellador a prueba de agua, dentro de una cubierta de material similar a la tubería a una distancia de al menos 10 pies de la parte mas cercana del sistema La cubierta de la línea de agua no puede ser colocada dentro de las 24 pulgadas de los SETAROS. Las líneas de agua dentro de los 5 pies del campo de drenaje no deben ser colocadas a una elevación mas baja que la superficie de absorción del campo de drenaje. Las líneas de agua no potable no deben ser colocadas dentro de las 24 pulgadas del sistema sin prevenir el flujo de retorno o revisar las válvulas instaladas en las líneas de agua para prevenir la contaminación del sistema de agua.

8. Los SETAROS deben ser colocados a 75 pies de la línea promedio de la superficie del agua de una zona de mareas de un cuerpo de agua.

9. Los SETAROS deben ser colocados a 75 pies de la línea promedio del nivel de inundación de agua de un cuerpo permanente aguas superficiales sin mareas.

10. Los SETAROS deben ser colocados a 15 pies de la línea del alto nivel de agua de un diseño para aguas de retención o embalses diseñados 
para retener el estancamiento o la corriente de agua durante por lo menos 72 horas después de una lluvia.

11. Los SETAROS deben ser colocados a 15 pies del nivel más alto del agua de un canal y áreas normalmente secos diseñados para retención de aguas de lluvia.

12. Los SETAROS deben ser colocados a 15 pies de los interceptores de drenaje de las aguas subterráneas.

13. El suelo de relleno nuevo, usado para instalar sistemas de pilas sépticas o reemplazar un suelo naturalmente no satisfactoriamente existente (ej., suelo no establecido), se exige que sea ligeramente limitado en su naturaleza y compactado a una densidad igual a la de los alrededores del suelo.

14. Los estándares especiales aplicados para la colocación de los sistemas en el suelo de piedra caliza, el cual es particularmente común en el Sur de Florida.

La zonificación del uso de la tierra del área donde el SETEROS está siendo instalado es también crucial. Si un área esta zonificado por una industria o fabrica, el DSF cerrará el sistema monitor para asegurar que éste recibe sustancias no toxicas o desechos peligrosos. Adicionalmente, el sistema no será permitido si esta disponible un sistema de desagüe publico. El tamaño del tanque y el campo de drenaje esta también prescrito por las reglas, las que enlistan los tamaños mínimos de los tanques, requeridos para cada tamaño de residencia u otro edificio. La reglamentación del tamaño esta basada en la cantidad de desecho, que estime el DSF, que se generará por cada tipo de edificio. El tamaño y las características de la tierra sobre la cual el tanque y el campo de drenaje van a ser instalados, es también prescrito por las reglas en las cuales la tierra del estado debe ser al menos dos veces el tamaño del campo de drenaje en si.

\section{¿Cómo Deberán Ser Mantenidos los Sistemas?}

El dueño de la propiedad es responsable por el mantenimiento del sistema. Es importante notar que un SETEROS debe ser operado bajo los términos de la regla y el permiso conforme el cual fue aprobado. El dueño no puede hacer cualquier cambio a la estructura o al sistema o incrementar el flujo de desagüe sin la aprobación del departamento de salud local. Conforme las reglas del DSF, el dueño deberá revisar el nivel del tanque como mínimo una vez cada tres años por un contratista de tanque séptico que este licenciado. Un contratista con licencia deberá también llevar a cabo cualquier mantenimiento necesario para el sistema. Si el triturador de basura o el desagüe comercial han estado descargando en un tanque, el propietario necesita tener inspeccionado el sistema una vez al año, por un contratista con licencia para tanque séptico o un plomero. Tanto los estatutos como las reglas prohíben el uso de solventes químicos orgánicos, tóxicos o químicos peligrosos, o productos del petróleo para desengrasar o destapar el sistema. A un contratista con licencia se le debe emitir un permiso de servicio anual antes de la remoción de los desechos encontrados en cualquier SETAROS.

\section{¿Cuáles Son los Procedimientos Para Un Tanque Séptico Abandonado?}

Son requeridos por DSF, un permiso y un pago para un tanque séptico abandonado, y deben seguirse estos pasos:

1. El tanque debe ser bombeado.

2. El fondo deberá ser abierto o roto para prevenir la retención del agua.

3. El tanque deberá ser rellenado con arena limpia $\mathrm{u}$ otro material conveniente y completamente con suelo.

4. Se debe hacer una inspección del sistema abandonado o por el DSF por la instalación local o autoridad de instalación de tuberías que efectúe el abandono del sistema. 


\section{¿Qué Permisos y Pagos Son Requeridos?}

El DSF requiere un permiso para la instalación, operación, reparación, alteración, modificación, reemplazo o abandono de todos los sistemas de desagüe en-sitio. Previo a la expedición de cualquier permiso, el DSF, los ingenieros profesionales de Florida con licencia u otras personas autorizadas, requieren de todos los sitios, una aplicación y un sitio de investigación. El DSF requerirá también una inspección completa del sistema séptico, antes de ser enterrado.

El DSF intenta llevar a cabo todas las inspecciones en un día de trabajo después que hayan sido notificados de que la instalación del tanque esta completada. Se cobrara un pago por el permiso, por las inspecciones y por cualquier otro servicio necesario ejecutado por el DSF. Generalmente, los rangos de los pagos son de $\$ 50$ a $\$ 200$, pero pueden ser elevarse a $\$ 500$ por una aplicación de pago por la aprobación de un producto innovador.

Es esencial notar que los gobiernos locales pueden tener requerimientos separados, incluyendo los permisos (ej., los permisos de instalación de tuberías), que pueden ser más estrictos que la ley o regla del estado. En muchos casos, la expedición de esos permisos estará dependiendo del solicitante, habiendo obtenido ya el permiso del DSF.

\section{¿Cuándo y Qué Sistemas Alternativos Pueden Ser Usados?}

Cuando es aprobado por el DSF del condado, los sistemas alternativos pueden, a discreción del solicitante, ser utilizados en circunstancias donde los sistemas estándares de sub-superficie no son aptos, o donde los sistemas alternativos son más factibles. Las reglas dejan a los departamentos individuales de salud del condado, como parte del DSF, la autoridad para aprobar los sistemas en sitio alternativos tal como un montículo, desagües por gravedad, baja presión de la tubería y otros sistemas hasta que el condado opine que no hay efectos adversos. Sin embargo, cualquier aprobación de los sistemas alternativos deben cumplir con la pertinente regla y ley. EL DSF del condado debe requerir la presentación de los planes preparados por un ingeniero registrado en el Estado de Florida antes de considerar el uso de cualquier sistema alternativo. El DSF retiene también la autorización para aprobar el uso de medidas temporales tales como inodoros portátiles. Las reglas del DSF también crean un Comité de Asesoría y Revisión de Varianza para escuchar solicitudes de variaciones. El comité puede asesorar al DSF para conceder una variación cuando se estime que no se puede cumplir un estricto cumplimiento con las leyes y reglas que rigen los sistemas de eliminación y tratamiento de desagües en el sitio. Sin embargo, solamente el DSF tiene la autoridad para otorgar una variación.

\section{Fuente}

Capitulo 381, de los Estatutos de Florida, Secciones 381.0065; Capitulo 64E-6, Código Administrativo de Florida

\section{Información de Contacto}

Manejo de los SETAROS (FE099, Agencias de Contacto)

S-5 Departamento de Salud de Florida (contactando al departamento de salud local del condado puede ser suficiente)

\section{Agradecimientos}

Los autores agradecen al personal de las agencias estatales y federales por su tiempo y asesoría en la preparación de este manual. Los autores agradecen especialmente a Richard Budell del Office of Agricultural Water Policy of the Florida Department of Agriculture and Consumer Services por el apoyo económico para el desarrollo de esta publicación. 